\title{
Fabrication and Characterization of Carbon-Based Nanofluids through the Water Vortex Trap Method
}

\author{
Ching-Min Cheng $\mathbb{D}^{1},{ }^{1}$ Shang-Pang $Y u\left(\mathbb{D},{ }^{1}\right.$ and Tun-Ping Teng $\mathbb{D}^{2}$ \\ ${ }^{1}$ Department of Mechatronic Engineering, National Taiwan Normal University, No. 162, Sec. 1, Heping E. Road, Da'an District, \\ Taipei City 10610, Taiwan \\ ${ }^{2}$ Department of Industrial Education, National Taiwan Normal University, No. 162, Sec. 1, Heping E. Road, Da'an District, \\ Taipei City 10610, Taiwan
}

Correspondence should be addressed to Shang-Pang Yu; ysb@ntnu.edu.tw

Received 29 December 2017; Revised 2 April 2018; Accepted 8 April 2018; Published 15 May 2018

Academic Editor: Kausala Mylvaganam

Copyright (C) 2018 Ching-Min Cheng et al. This is an open access article distributed under the Creative Commons Attribution License, which permits unrestricted use, distribution, and reproduction in any medium, provided the original work is properly cited.

\begin{abstract}
This study designed an efficient one-step method for synthesizing carbon-based nanofluids (CBNFs). The method employs the vortex trap method (VTM) and an oxygen-acetylene flame, serving as a carbon source, in a manufacturing system of the VTM (MSVTM). The flow rate ratio of $\mathrm{O}_{2}$ and $\mathrm{C}_{2} \mathrm{H}_{2}$ was adjusted to form suitable combustion conditions for the reduced flame. Four flow rate ratios of $\mathrm{O}_{2}$ and $\mathrm{C}_{2} \mathrm{H}_{2}$ were used: $1.5: 2.5$ (V1), $1.0: 2.5$ (V2), $0.5: 2.5$ (V3), and $0: 2.5$ (V4). The morphology, structure, particle size, stability, and basic physicochemical characteristics of the obtained carbon-based nanomaterials (CBNMs) and CBNFs were investigated using transmission electron microscopy, field-emission scanning electron microscopy, X-ray diffraction, Raman spectrometry, ultraviolet-visible-near-infrared spectrophotometry, and a particle size-zeta potential analyzer. The static positioning method was utilized to evaluate the stability of the CBNFs with added EP dispersants. The evaluation results revealed the morphologies, compositions, and concentrations of the CBNFs obtained using various process parameters, and the relation between processing time and production rate was determined. Among the CBNMs synthesized, those obtained using the V4-0 flow rate ratio had the highest stability when no EP dispersant was added. Moreover, the maximum enhancement ratios of the viscosity and thermal conductivity were also obtained for V4-0: $4.65 \%$ and $1.29 \%$, respectively. Different types and concentrations of dispersants should be considered in future research to enhance the stability of CBNFs for further application.
\end{abstract}

\section{Introduction}

Nanofluids (NFs) are solid-liquid mixtures containing nanoscale materials such as nanoparticles (NPs), nanofibers, nanotubes, nanowires, nanorods, nanosheets, and droplets. The base fluids are commonly used fluids such as ethylene glycol (EG), mineral oil, or a mixture of various liquids (e.g., EG and water or water and propylene glycol) $[1,2]$. The primary advantage of NFs is that they have superior thermophysical properties to conventionally used fluids. These superior thermophysical properties result in higher efficiency of their heat exchange [3, 4]. Moreover, the addition of nanoscale particles to NFs can result in considerably lower pressure drops, blocks, wear, and energy consumption in heat exchange system pipelines, thereby improving the availability of NFs. Therefore, NFs have numerous potential applications in engineering, especially in the fields of electromechanics, air conditioning, automobiles, manufacturing, machining, solar energy, building structures, and biomedicine [5-10].

The NF synthesis methods can be divided into two categories-one-step and two-step methods. In the one-step method, NPs are directly synthesized in base fluids; thus, the synthesized NFs have high stability. However, the geometric appearance and size of the NPs and the concentration of the NFs are limited. In the two-step method, NPs are synthesized in advance and then distributed in the base fluid to form an NF. The concentration and particle size distribution of the NFs produced in the two-step method can be easily controlled; however, these NFs have low stability. Therefore, it is crucial to improve the long-term stability of NFs by adding 
dispersants and conducting $\mathrm{pH}$ control, mechanical stirring, and dispersion $[5,11]$.

The one-step methods for producing NFs, such as sputtering arc discharge, laser ablation, water-assisted synthesis, and flame synthesis, are the most common. Ishida et al. [12] prepared thiolate-protected fluorescent silver NPs by conducting sputtering deposition onto a liquid matrix. Nguyen et al. $[13,14]$ synthesized Ag-Au alloy NPs in a liquid by utilizing a novel approach known as double target sputtering. This method allows the manipulation of NP composition, size, and optical properties by controlling the sputter parameters for each metal target. Farajimotlagh et al. [15] synthesized $\eta-\mathrm{Al}_{2} \mathrm{O}_{3}$ NPs by conducting directcurrent arc discharge in ethanol and methanol, which are environmentally friendly liquid carrier media. The size of the synthesized NPs was between 37 and $50 \mathrm{~nm}$. Hayashi et al. [16] prepared hydrophilic carbon NPs (CNPs) from amino acids by conducting pulsed arc discharge over an aqueous solution surface under pressurized argon at $4 \mathrm{MPa}$. This method produced CNPs that were highly dispersible in water because the amino acids provided hydrophilic groups. Zhang et al. [17] efficiently prepared silver NPs by using large-area arc discharge in a liquid. The minimum size of the synthesized silver NPs was $33 \mathrm{~nm}$. Amans et al. [18] reviewed the nanocarbon material preparation methods that employed a pulse laser in a liquid. Palazzo et al. [19] prepared "naked" gold NPs (AuNPs) in the absence of capping agents by performing pulsed laser ablation in a liquid; these AuNPs were stabilized by negative charges. Krstulović et al. [20] prepared colloidal Al-doped $\mathrm{ZnO}$ NPs by using Nd:YAG pulsed laser ablation of a $\mathrm{ZnO}: \mathrm{Al}_{2} \mathrm{O}_{3}$ target with two laser wavelengths (1064 and $532 \mathrm{~nm}$ ) in a water medium. The size of the synthesized Aldoped $\mathrm{ZnO}$ NPs was between 20 and $30 \mathrm{~nm}$. Sathya et al. [21] presented a simple, one-step approach named microwaveassisted synthesis for the preparation of water-dispersible magnetic nanoclusters (MNCs) of superparamagnetic iron oxide; this method involved reducing $\mathrm{Fe}_{2}\left(\mathrm{SO}_{4}\right)_{3}$ in sodium acetate, polyethylene glycol, and EG within a microwave reactor. The average size of the MNCs increased from 27 to $52 \mathrm{~nm}$ as the reaction time was increased from 10 to $600 \mathrm{~s}$. Golestan et al. $[22,23]$ studied nanocatalysts that were synthesized through a hydrothermal procedure in a fixed-bed reactor. Teng et al. [24] fabricated nanocarbon-based NFs using the oxygen-acetylene flame synthesis method. By adjusting the oxygen-acetylene ratio, the size of the synthesized CNPs was varied between 20 and $30 \mathrm{~nm}$. In the present study, the oxygen-acetylene flame synthesis method was employed to produce CNPs, and hybrid NFs were collected using vortex trap equipment. This method is a fast, efficient, simple, and energy-conserving approach to the synthesis of carbon NFs.

In recent years, numerous studies of materials such as nanocarbons, carbon nanotubes, and graphene have been conducted and have discovered that these materials have high thermal conductivity [25-28], excellent heat transfer performance $[29,30]$, and physical properties that are unique for such materials [21-34]. Therefore, carbon-based nanomaterials are one of the most popular research areas. This study employed the vortex trap method (VTM) with an oxygen $\left(\mathrm{O}_{2}\right)$-acetylene $\left(\mathrm{C}_{2} \mathrm{H}_{2}\right)$ flame as the carbon source to develop a manufacturing system of the VTM (MSVTM) for fabricating carbon-based NFs (CBNFs) through the onestep synthesis method. The MSVTM has features such as a simplistic system design, low-cost production, convenient and safe manufacturing procedures, and no requirement of additional chemicals. Moreover, the CBNFs produced using the one-step synthesis method generally have high suspension performance because of the optimal surface wettability of the suspended nanoparticles. The MSVTM was used at various flow rate ratios of $\mathrm{O}_{2}$ and $\mathrm{C}_{2} \mathrm{H}_{2}$ to produce varying combustion conditions of the reduced flame. The morphology, structure, particle size, suspension performance, and basic physicochemical characteristics of the carbon-based nanomaterials (CBNMs) and CBNFs were investigated by utilizing appropriate techniques such as transmission electron microscopy (TEM), field-emission scanning electron microscopy (FE-SEM), X-ray diffraction (XRD), Raman spectrometry, ultraviolet-visible-near-infrared spectrophotometry (UV-Vis-NIR), and a particle size-zeta potential analyzer. Moreover, the feasibility of manufacturing CBNFs by using the MSVTM was evaluated.

\section{Preparation of CBNFs}

The one-step synthesis method known as the VTM was employed to prepare CBNFs. The layout of the MSVTM for synthesizing CBNFs is displayed in Figure 1. An $\mathrm{O}_{2}-\mathrm{C}_{2} \mathrm{H}_{2}$ flame was utilized as the carbon source. The MSVTM comprised curved baffles, baffles with a labyrinth structure, a jagged baffle, a smoke cover, a collection tank, an exhaust fan, a digital mass flow controller (MFC), an electromagnetic stirrer, and an $\mathrm{O}_{2}-\mathrm{C}_{2} \mathrm{H}_{2}$ torch. As shown in Figure 1, filtered tap water was placed in the collection tank. Subsequently, the electromagnetic stirrer (HMS-102, FARGO, Taiwan) was turned on at approximately $500 \mathrm{rpm}$ to create a disturbance in the water and to increase the cooling and collection efficiency on the water surface for suspended particles in air at stage 1 . Finally, the exhaust fan was switched on to produce air flow (approximately $0.2 \mathrm{~m}^{3} / \mathrm{s}$ ), which generated negative pressure in the MSVTM and sucked air from the front of the jagged baffle. Due to the asymmetric shape of the jagged baffle's holes and the change in the internal structure and configuration of the jagged baffle, a strong disturbance was caused in the intake air of the MSVTM. Moreover, the strong disturbance in the intake air produced a vortex that splashed the water to cool and collect the suspended particles in the air. An MFC was used to control the flow rate and $\mathrm{O}_{2}-\mathrm{C}_{2} \mathrm{H}_{2}$ ratio, while a flame was produced using the $\mathrm{O}_{2}-\mathrm{C}_{2} \mathrm{H}_{2}$ torch. The $\mathrm{O}_{2}-\mathrm{C}_{2} \mathrm{H}_{2}$ flame was used as a carbon source and was lit under a smoke cover over the water surface. The smoke generated by the $\mathrm{O}_{2}-\mathrm{C}_{2} \mathrm{H}_{2}$ flame was sucked into the MSVTM. Therefore, the smoke was cooled and condensed by the disturbed water (stage 1) and splashing water (stages 2 and 3 ) to form a CBNM. When the mixture of CBNM and water had flowed into the collection tank, CBNFs were produced. This CBNF manufacturing technology has considerable potential.

The manufacturing process parameters of the MSVTM for yielding CBNFs are detailed as follows. The amount of water in the collection tank was $2 \mathrm{~L}$ for each process; the $\mathrm{C}_{2} \mathrm{H}_{2}$ 


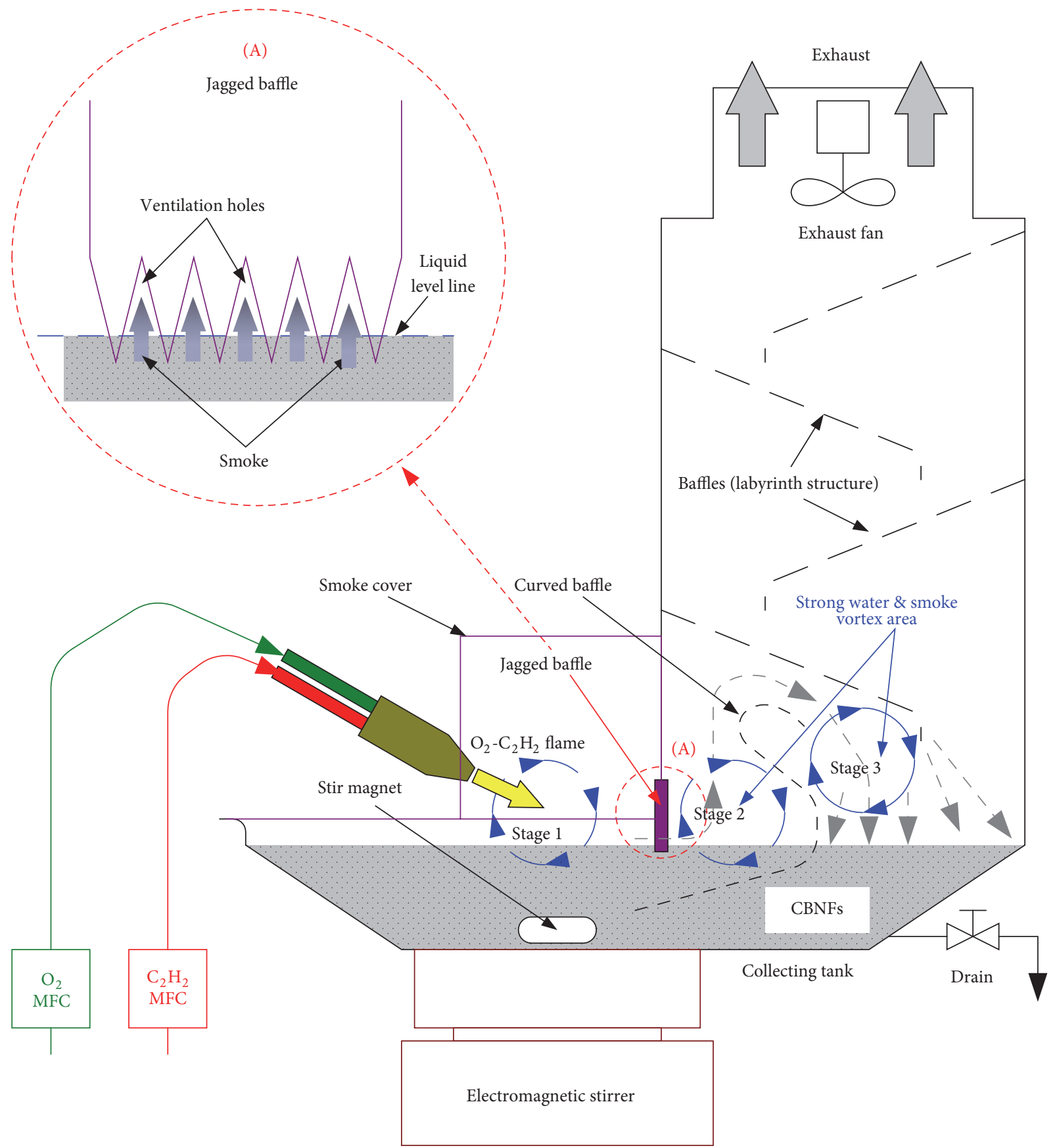

FIgURE 1: Schematic of the MSVTM for preparing CBNFs.

flow rate was fixed at $2.5 \mathrm{~L} / \mathrm{min}$ at a pressure of $1.5 \mathrm{~kg} / \mathrm{cm}^{2}$; and the $\mathrm{O}_{2}$ flow rate was controlled in the range $0-1.5 \mathrm{~L} / \mathrm{min}$ at a pressure of $3.0 \mathrm{~kg} / \mathrm{cm}^{2}$. The flow ratio and pressure settings of $\mathrm{C}_{2} \mathrm{H}_{2}$ and $\mathrm{O}_{2}$ were based on the settings used in previous studies [24]. The $\mathrm{O}_{2}-\mathrm{C}_{2} \mathrm{H}_{2}$ fuel was employed in four flow ratio configurations-V1 $(1.5: 2.5), \mathrm{V} 2(1.0: 2.5), \mathrm{V} 3(0.5: 2.5)$, and V4 $(0: 2.5)$. The flame was a reduction flame because the $\mathrm{O}_{2}$ proportion was lower than the $\mathrm{C}_{2} \mathrm{H}_{2}$ proportion. An increase in the proportion of oxygen in the $\mathrm{O}_{2}-\mathrm{C}_{2} \mathrm{H}_{2}$ flame was expected to result in more complete combustion, less smog, and less CBNM. In this study, each flow ratio configuration was employed for 3, 6, 9, and $12 \mathrm{~min}$; thus, a total of 16 CBNF samples were obtained. In the combustion process, some water vaporized; thus, water was frequently replenished to maintain the water level in the tank. When the CBNFs were removed from the collection tank, $1 \mathrm{~L}$ of water was slowly poured into the collection tank to drain the carbon attached to the collection tank. The volume of CBNFs yielded per process parameter and time configuration was approximately $3 \mathrm{~L}$.

To improve the suspension and dispersion performance of the CBNMs in water, the collected CBNFs were stirred 


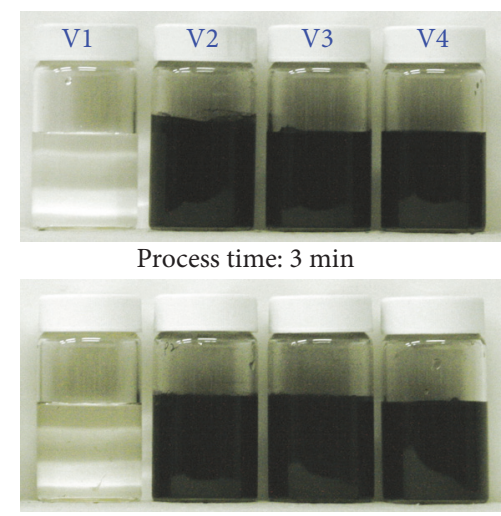

Process time: $12 \mathrm{~min}$

(a) Initial state

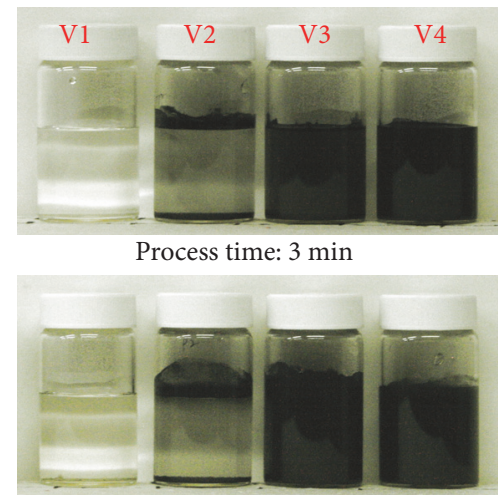

Process time: $12 \mathrm{~min}$

(b) After 48 hours

FIGURE 2: Photographs of CBNFs obtained using various process parameter configurations.

using a stirrer/hot plate (PC420D, Corning, USA) operated at $450 \mathrm{rpm}$ for $2 \mathrm{~h}$, after which they were homogenized at $5000 \mathrm{rpm}$ for $20 \mathrm{~min}$ using a homogenizer (YOM300D, Yotec, Taiwan). Subsequently, the CBNFs were bathed in an ultrasonic bath (5510R-DTH, Branson, USA) for $30 \mathrm{~min}$ and then subjected to an intermittent oscillation process $(35 \%$ amplitude, on/off duty cycle was $30 / 10 \mathrm{~s}$ ) by using an ultrasonic liquid processor (Q700, Qsonica, USA) for $10 \mathrm{~min}$. By using these dispersing devices consecutively and three times for short periods, temperature increases in the dispersing devices and the CBNFs were effectively prevented, thus achieving excellent dispersion. This technique was employed on the basis of the authors' research experience. Figure 2(a) displays photographs of the CBNFs fabricated using various process configurations. In contrast to the V1 CBNFs, which were almost transparent, the other CBNFs were dark. Figure 2(b) displays all the samples that were statically placed for $48 \mathrm{~h}$ to evaluate their suspension status; the V2 CBNFs exhibited obvious sedimentation. After dispersed CBNFs were produced, they were subjected to a series of examinations for determining their characteristics.

\section{Evaluation of the Characteristics of the CBNFs}

3.1. Morphology, Crystallization, and Structure Analyses. TEM (H-7100, Hitachi, Japan) and FE-SEM (JSM-7610F, JEOL, Japan) were used to identify the morphologies of the obtained CBNMs in the CBNFs. The shapes and sizes of the CBNMs were determined. The crystallization of the CBNMs was analyzed using XRD (D8 Advanced, Bruker, Germany) with $\mathrm{Cu} \mathrm{K} \alpha$ radiation. Raman spectroscopy (532.15 nm, NRS 4100, Jasco, Japan) was employed to detect the Raman shift in the $D$ and $G$ peaks of the CBNM spectra. The CBNFs were placed on glass sheets $\left(20 \times 20 \times 0.6 \mathrm{~mm}^{3}\right)$ and dried by heating to form carbon films in advance of conducting XRD and Raman spectroscopy. Because the concentrations of the V1 CBNFs were extremely low, a vacuum concentrator was used to increase the concentration of the test samples for all the aforementioned measurements.
3.2. Production Rate Analysis. The CBNM production rate for each process parameter configuration was measured for determining the concentration of CBNMs in the CBNFs [24]. A moisture analyzer (MX-50, A\&D, Japan) was used to remove moisture from a $25 \mathrm{~g}$ sample of each CBNF by heating, and the remaining weight was utilized (weighing method) to estimate the CBNM concentration in the CBNF sample. Samples were weighed before and after drying. Because the highest resolution of the moisture analyzer was only $1.0 \mathrm{mg}$, a high-precision electronic balance (0.01 mg/42 g, GR202, A\&D, Japan) was employed to improve the weighing accuracy. The entire weighing procedure was repeated four times, and the average value of test data was calculated to determine the CBNM content weight of a CBNF for each process parameter configuration. Finally, the actual weight concentration in each CBNF was obtained from the CBNM content weight and CBNF sample weight.

3.3. Stability Analysis. To appropriately employ the stability test and facilitate the stability comparison (suspension and dispersion performance), samples that were synthesized using various process parameters were adjusted to the same concentration by diluting with water or concentrating with a vacuum concentrator, because the concentrations of all the CBNFs were not equal. Moreover, if a CBNF had poor stability, the accuracy and reliability of the characteristic measurements were affected. Figure 2 displays that V2 had poor stability, and obvious sedimentation was observed through static positioning. Hence, the stability of each sample was tested by adding a nonionic dispersant (EP dispersant, polyoxyethylene alkyl ether; EP9050, First Chemical, Taiwan) in various concentrations. The samples with optimal stability were subjected to the following measurements of particle size $\left(d_{p}\right)$, zeta potential $(\zeta)$, and basic physicochemical characteristics. To determine their stability, the CBNFs were mainly tested using static positioning and UV-Vis-NIR (V670, Jasco, Japan). An elaborate account of the static positioning method is provided as follows. First, a CBNF was placed into a transparent sample bottle, and the sediment difference was visually observed after $120 \mathrm{~h}$. To measure the difference 
in the absorbance at the initial $\left(\mathrm{ABS}_{i}\right)$ and static position for each CBNF after $48 \mathrm{~h}\left(\mathrm{ABS}_{48 \mathrm{~h}}\right), \mathrm{UV}-\mathrm{Vis}-\mathrm{NIR}$ combined with static positioning (2.5-mL CBNF sample in a transparent cuvette) was performed. The absorbance difference ratio $\left(R_{\mathrm{ABS}}\right)$ was calculated using $(1)$ and utilized to determine the stability of the CBNF. A lower $R_{\mathrm{ABS}}$ represents a higher CBNF stability.

$$
R_{\mathrm{ABS}}=\left[\frac{\left(\mathrm{ABS}_{i}-\mathrm{ABS}_{48 \mathrm{~h}}\right)}{\mathrm{ABS}_{i}}\right] \times 100 \% .
$$

Moreover, the stability of a CBNF can be evaluated using the suspended $d_{p}$ distribution, average suspended $d_{p}$, and $\zeta$. The suspended $d_{p}$ of CBNMs is similar to the $d_{p}$ is observed using electron microscopy, thus indicating the favorable dispersion of the CBNMs in the CBNFs. Moreover, the larger the absolute value of $\zeta$, the higher the stability of an CBNF. The $\zeta$ values of the colloidal dispersions were within the ranges 0 to $\pm 10, \pm 10$ to $\pm 30, \pm 30$ to \pm 40 , and \pm 40 to $\pm 60 \mathrm{mV}$; these values indicated rapid coagulation or flocculation, incipient instability, moderate stability, and favorable stability, respectively. When the magnitude of the $\zeta$ of a NF is greater than $60 \mathrm{mV}$, the colloidal dispersion has excellent stability $[35,36]$. The dynamic light-scattering method was conducted for $d_{p}$ and $\zeta$ analysis. A CBNF into which a $6 \mathrm{~mm}$ gold-plated electrode cell was placed was simultaneously measured by using a nanoparticle analyzer (SZ-100, HORIBA, Japan) to evaluate the average $d_{p}$, the $d_{p}$ distribution, and $\zeta$. The $d_{p}$ and $\zeta$ values for each CBNF were measured five times, and the average $d_{p}$ and $\zeta$ were then calculated.

3.4. Basic Physicochemical Characteristic Measurements. The basic physicochemical characteristics measured for the CBNFs were $\mathrm{pH}$, electrical conductivity $(E)$, density $(\rho)$, viscosity $(\mu)$, and thermal conductivity $(k)$, which were measured using a $\mathrm{pH}$ meter (SensION+ MM374, Hack, USA) with an accuracy of $\pm 0.002 \mathrm{pH}$ and $\pm 0.5 \%$, an electrical conductivity meter (SensION+ MM374), a liquid density meter (DA-130N, KEM, Japan) with an accuracy of $\pm 0.001 \mathrm{~g} / \mathrm{mL}$, a viscosity meter (T15-3, Hydramotion, England) with an accuracy of $\pm 1.0 \%$, and a thermal properties analyzer (KD2 Pro, Decagon Devices, USA) with an accuracy of $\pm 5.0 \%$, respectively. These measurements were made in an isothermal bath (P-20, YSC, Taiwan) to provide individual sample temperature control of 30,40 , or $50^{\circ} \mathrm{C}$ within $\pm 0.5^{\circ} \mathrm{C}$. To increase the experimental accuracy, these experiments were conducted six times, and the four most similar values were used to obtain the average.

In a high-purity nitrogen $(5 \mathrm{~N})$ atmosphere, the specific heat $\left(c_{p}\right)$ of the test samples was measured using a differential scanning calorimeter (DSC, Q20, TA, USA) with a mechanical refrigeration system (RCS40, TA, USA). The temperature and calorimetric accuracies of the DSC were $\pm 0.1^{\circ} \mathrm{C}$ and $\pm 1.0 \%$, respectively. The $c_{p}$ test method used was the standard reference approach, and the standard reference was pure water [37]. The experimental temperature was between 10 and $80^{\circ} \mathrm{C}$, and the heating rate was maintained at $10^{\circ} \mathrm{C} / \mathrm{min}$. To increase the measurement accuracy, the experiments were conducted thrice for each CBNF, and the average $c_{p}$ value of the CBNF was then calculated.
3.5. Data Analysis. The experimental results were transformed into a change ratio (CR) for comparison of water with the CBNFs; the CR can be expressed as

$$
\mathrm{CR}=\left[\frac{\left(D_{\mathrm{CBNFs}}-D_{w}\right)}{D_{w}}\right] \times 100 \% .
$$

\section{Results and Discussion}

Figures 3 and 4 display TEM and FE-SEM images of the CBNMs obtained using the four process flow ratio configurations (V1-V4) and processing times of 3 and $12 \mathrm{~min}$. Spherical CBNMs ( $d_{p}$ : approximately $20-50 \mathrm{~nm}$ ) were synthesized mostly when the V2-V4 configurations were used, whereas flaky CBNMs were mostly obtained using V1. Flaky CBNMs were thus obtained when the proportion of $\mathrm{O}_{2}$ was increased. Conversely, a high proportion of $\mathrm{C}_{2} \mathrm{H}_{2}$ contributed to the formation of CBNMs with more spherical particles. Moreover, the processing time of the MSVTM was not discovered to affect the particle size and morphology of the CBNMs. The FE-SEM and TEM images of CBNMs indicate that processing time did not affect $d_{p}$ for parameter configurations V2-V4, but differences were observed when V1 was employed. Although FE-SEM and TEM images can partially display $d_{p}$ and morphology, a nanoparticle analyzer was required to confirm the $d_{p}$ distribution and average $d_{p}$ of the suspended CBNMs in CBNFs. Moreover, XRD and Raman spectroscopy were necessary to identify the material in the follow-up tests.

Figure 5 displays XRD patterns of the CBNMs that were synthesized by employing V1-V4. The CBNMs could barely be distinguished. However, dissimilarities existed within the composition and crystalline state of the samples. By using XRD, we observed that the (001) diffraction peak was located at a $2 \theta$ value of $11^{\circ}$ and that graphene oxide (GO) was the primary constituent of most of the CBNMs. The peaks at $2 \theta$ between $21^{\circ}$ and $27^{\circ}$ suggest that this range overlaps the (002) diffraction peak of graphite, which has a $2 \theta$ of $26.5^{\circ}$. A broad diffraction peak at $2 \theta$ between $23^{\circ}$ and $24^{\circ}$ is observed in Figure 5. In some materials, most of the functional groups had been removed, which provides clear evidence that some amount of reduced GO (RGO) was present in these CBNMs [38-40]. The CBNMs were generated by using an $\mathrm{O}_{2}-\mathrm{C}_{2} \mathrm{H}_{2}$ reduction flame, and reduction gases such as carbon monoxide were present in the combustion products of the reduction flame. Moreover, a very small amount of free oxygen was present to produce different degrees of reduction reactions. The reduction reaction caused the functional groups in the internal layers of GO to gradually disappear, and thus, GO was gradually reduced to RGO [38-40]. Furthermore, the crystallization of the CBNMs for various process parameters was inferior due to the broad range of the (002) diffraction peak. Hence, in this study, amorphous carbon (AC) was included, and different proportions of GO, RGO, and AC were required to synthesize CBNMs by using different process parameter configurations.

The Raman spectra displayed in Figure 6 were used to determine the structure of the CBNMs synthesized using V1-V4. The test samples had three test points, and one of the three test points was chosen for Figure 6. Table 1 presents the 


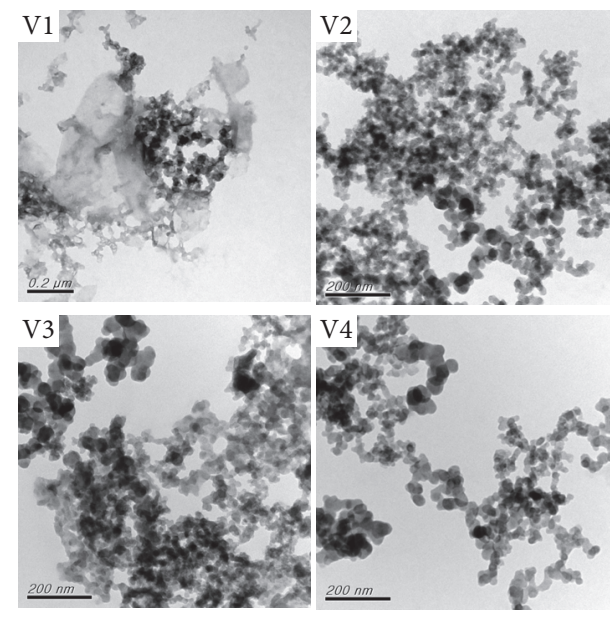

(a)

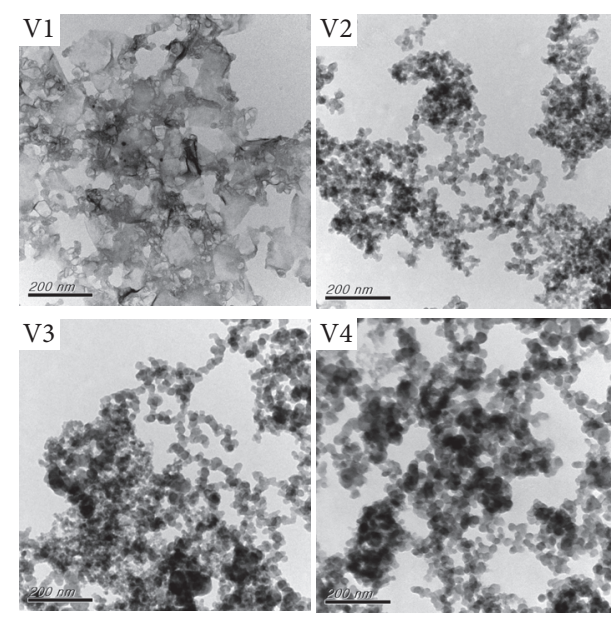

(b)

FIGURE 3: TEM images of CBNMs obtained using various process parameters for processing time durations of (a) 3 and (b) 12 min.

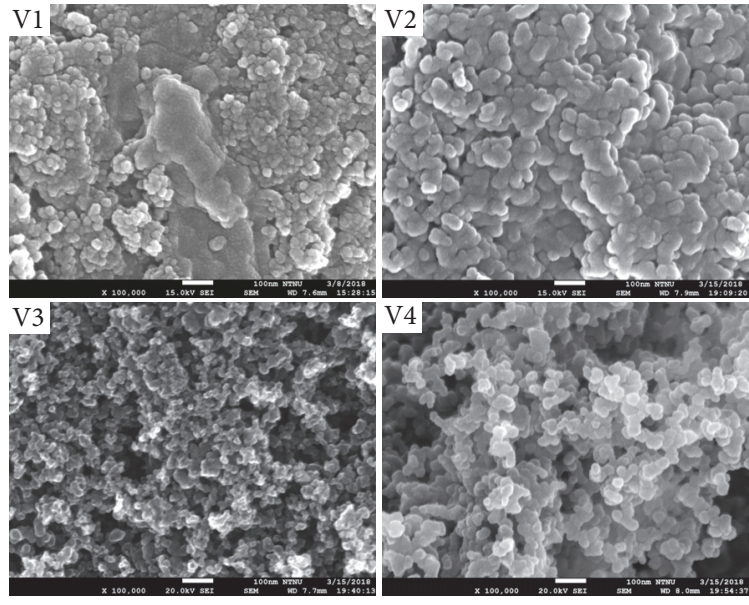

(a)

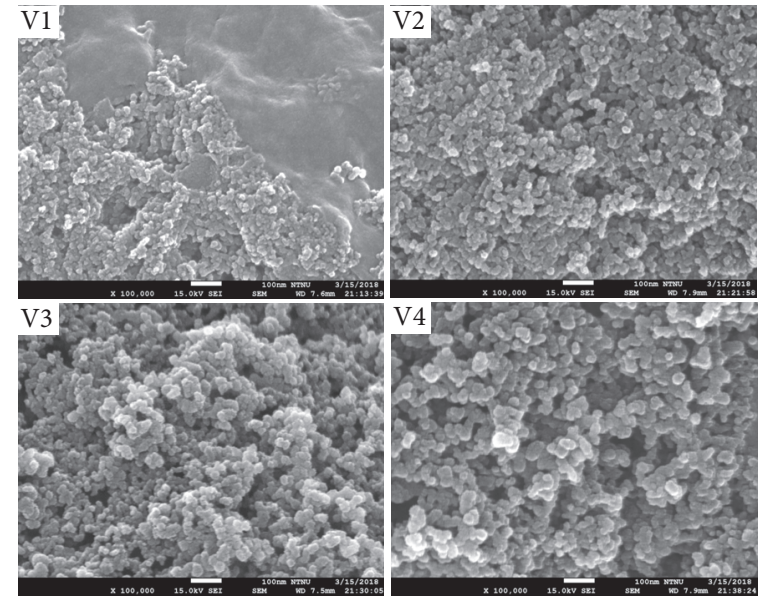

(b)

FIGURE 4: FE-SEM images of CBNMs obtained using various process parameters for processing time durations of (a) 3 and (b) 12 min.

TABLE 1: Averaged Raman spectroscopy data for the CBNFs obtained using various process parameter configurations.

\begin{tabular}{|c|c|c|c|c|c|c|c|c|}
\hline \multirow{2}{*}{ Item } & \multicolumn{4}{|c|}{$3 \mathrm{~min}$} & \multicolumn{4}{|c|}{$12 \mathrm{~min}$} \\
\hline & V1 & $\mathrm{V} 2$ & V3 & V4 & V1 & $\mathrm{V} 2$ & V3 & V4 \\
\hline \multicolumn{9}{|l|}{$I_{\mathrm{D}}$} \\
\hline $\mathrm{cm}^{-1}$ & 1346.65 & 1336.04 & 1339.41 & 1349.34 & 1344.86 & 1337.61 & 1340.95 & 1342.19 \\
\hline Int. & 230.48 & 184.43 & 118.52 & 51.25 & 194.21 & 205.81 & 297.88 & 71.23 \\
\hline \multicolumn{9}{|l|}{$I_{\mathrm{G}}$} \\
\hline $\mathrm{cm}^{-1}$ & 1592.65 & 1590.37 & 1589.41 & 1595.34 & 1589.86 & 1592.28 & 1587.61 & 1600.86 \\
\hline Int. & 308.35 & 143.41 & 140.69 & 83.85 & 261.63 & 163.47 & 288.46 & 121.64 \\
\hline \multicolumn{9}{|l|}{$I_{2 \mathrm{D}}$} \\
\hline $\mathrm{cm}^{-1}$ & 2639.65 & 2649.70 & 2634.74 & 2636.67 & 2651.86 & 2651.61 & 2638.95 & 2633.53 \\
\hline Int. & 10.54 & 25.63 & 10.23 & 10.06 & 7.17 & 21.01 & 21.73 & 13.45 \\
\hline$I_{\mathrm{D}} / I_{\mathrm{G}}$ & 0.75 & 1.29 & 0.84 & 0.61 & 0.74 & 1.26 & 1.03 & 0.59 \\
\hline$I_{2 \mathrm{D}} / I_{\mathrm{G}}$ & 0.03 & 0.18 & 0.07 & 0.12 & 0.03 & 0.13 & 0.08 & 0.11 \\
\hline
\end{tabular}

Note. Data are the average of three measurement points for each sample. 

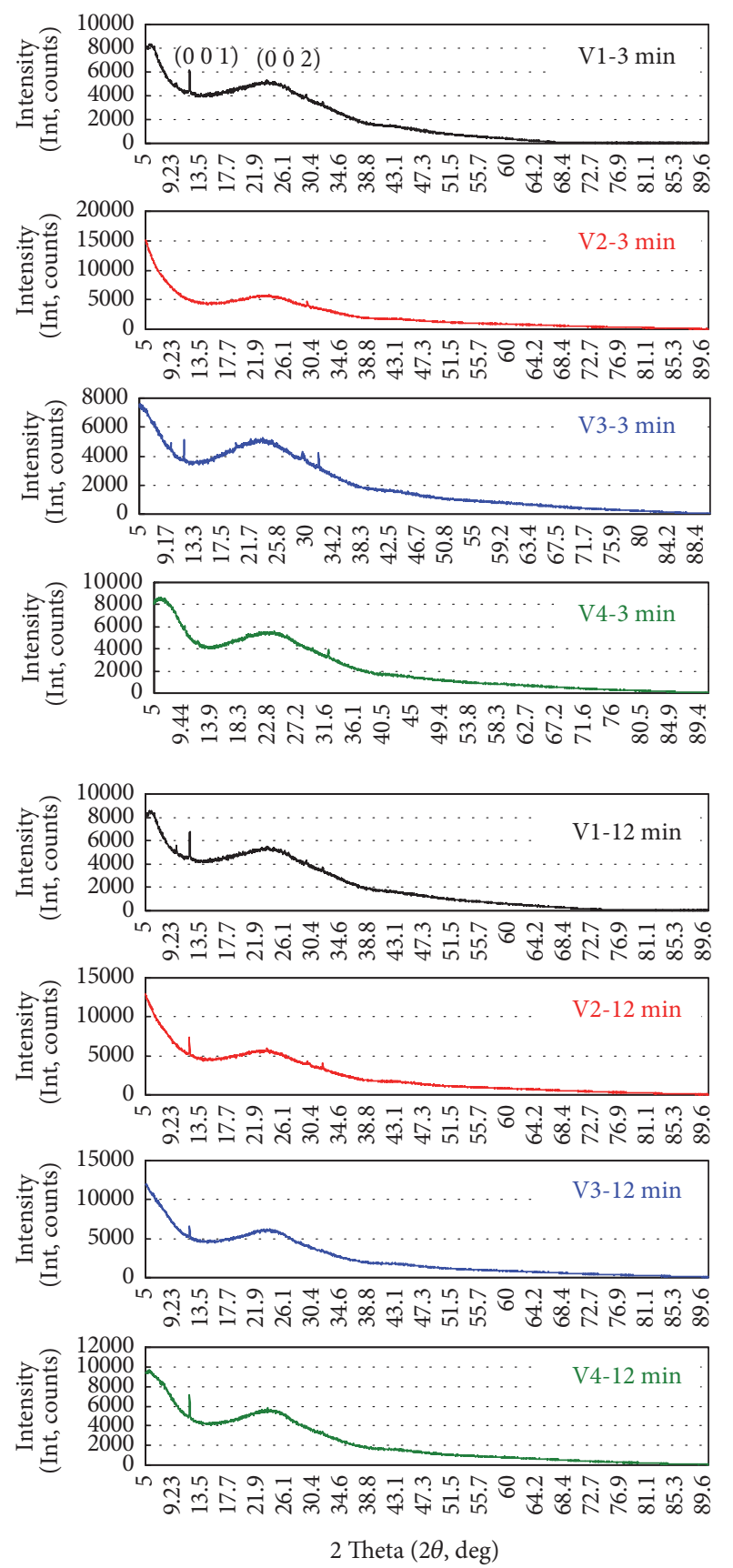

FIGURE 5: XRD patterns of CBNMs obtained using various process parameter configurations.

average data obtained from the Raman spectra for the three test points. In the Raman spectra, the D and G peaks, located at approximately $1324-1346 \mathrm{~cm}^{-1}$ and $1490-1691 \mathrm{~cm}^{-1}$, respectively, are the predominant features $[7,41-44]$. In general, the spectrum of pristine graphite has a prominent $\mathrm{G}$ peak at $1584.5 \mathrm{~cm}^{-1}$ that corresponds to first-order scattering of the E2g mode in the Brillouin zone. This indicates that the structure of graphite is regular [7, 42-45]. In the Raman spectrum of GO, the G peak is broadened and the D peak is prominent, thus indicating that the $\mathrm{C}=\mathrm{C}$ bonds in the graphite layers are destroyed by oxidation and that several

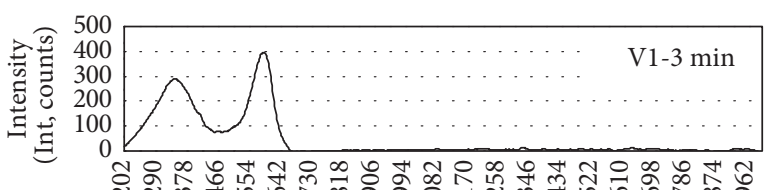

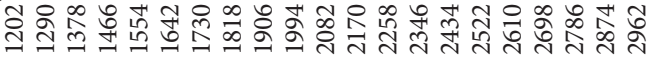

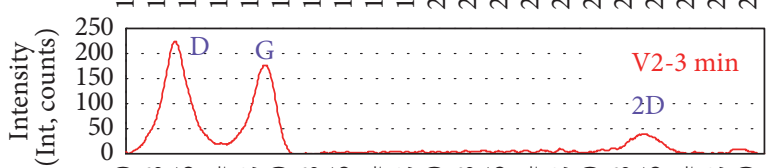

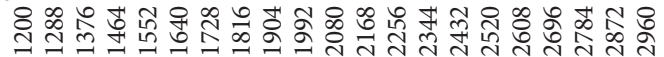

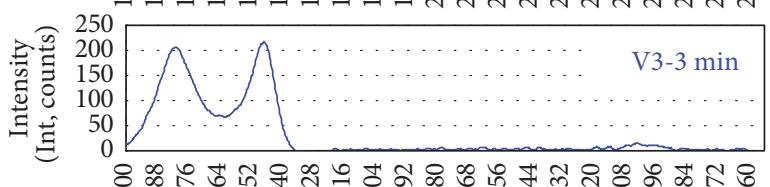

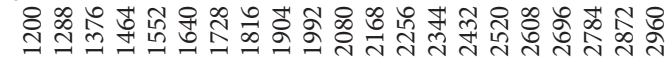
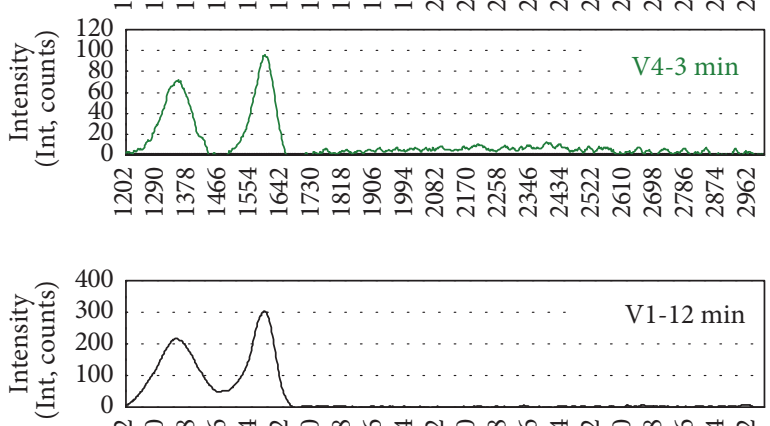

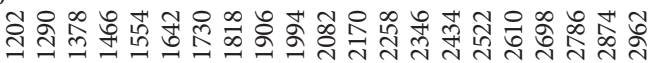
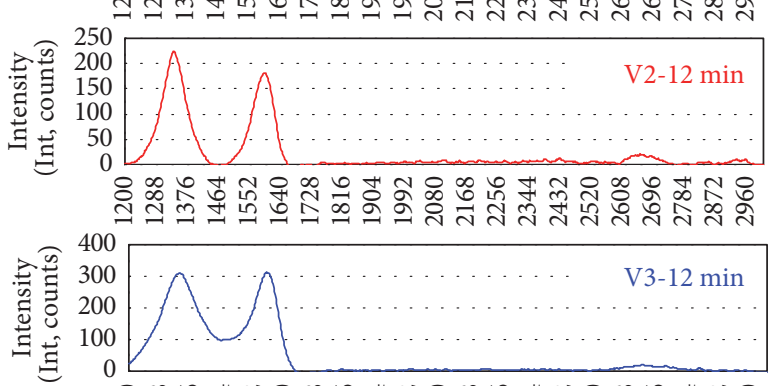

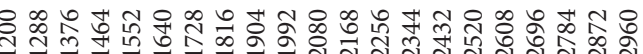

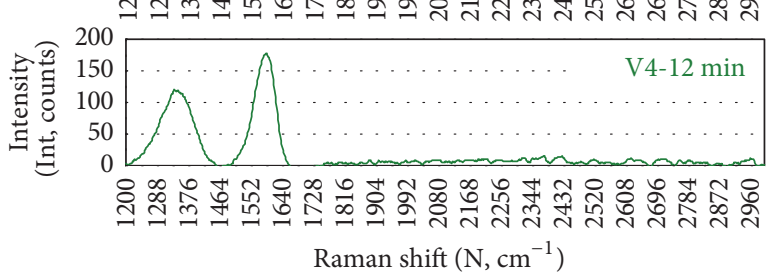

FIGURE 6: Raman spectra of CBNMs obtained using various process parameter configurations.

carbon atoms change from $\mathrm{sp}^{2}$ - to $\mathrm{sp}^{3}$-hybridized carbon. The intensity $I_{\mathrm{D}} / I_{\mathrm{G}}$ represents the ratio of $\mathrm{sp}^{3}$ - and $\mathrm{sp}^{2}$-hybridized carbon atoms. In RGO, $I_{\mathrm{D}} / I_{\mathrm{G}}$ is directly proportional to the number of $\mathrm{sp}^{3}$-hybridized atoms but inversely proportional to the number of $\mathrm{sp}^{2}$-hybridized atoms. Theoretically, $I_{\mathrm{D}} / I_{\mathrm{G}}$ declines as GO is reduced to RGO. Moreover, a smaller $I_{\mathrm{D}} / I_{\mathrm{G}}$ indicates more complete reduction of $\mathrm{GO}$ to $\mathrm{RGO}$ $[41,46]$. However, when GO is incompletely reduced, $I_{\mathrm{D}}$ is greater than $I_{\mathrm{G}}$. In addition, some studies have demonstrated that the reduction of GO to RGO by utilizing the chemical 


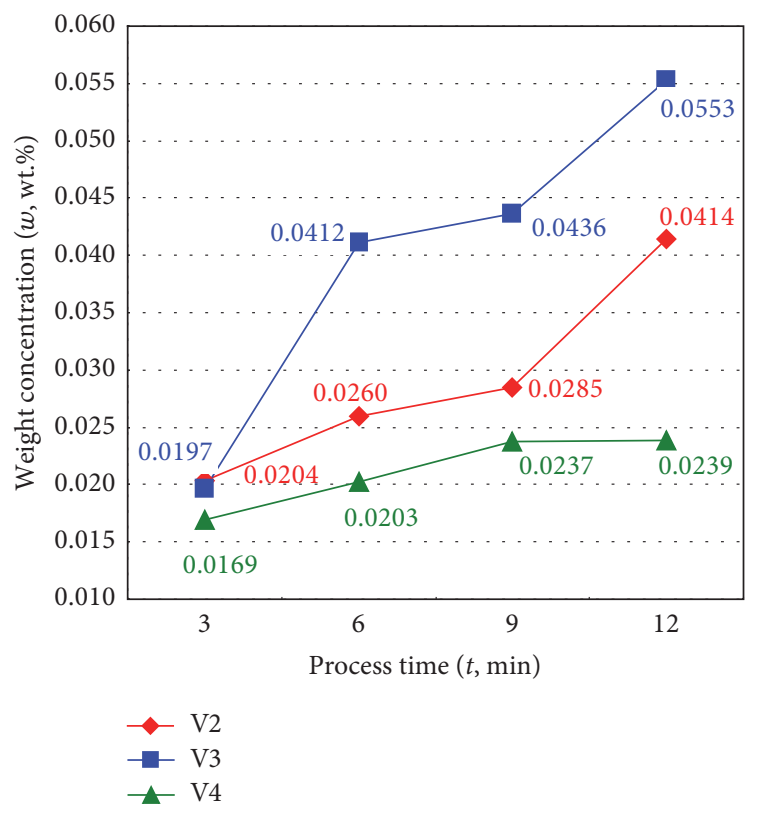

FIgURE 7: Concentrations of CBNFs obtained using various process parameter configurations.

reduction method caused an increase in $I_{\mathrm{D}} / I_{\mathrm{G}}$ [47-50]. This mainly occurs because reduction increases the number of small aromatic domains in GO, leading to an increase in the $I_{\mathrm{D}} / I_{\mathrm{G}}$ ratio [47]. As shown in Figure 6 and Table 1 , regardless of the processing time ( 3 or $12 \mathrm{~min}$ ) and parameter configuration $(\mathrm{V} 1-\mathrm{V} 4)$, the $I_{\mathrm{D}} / I_{\mathrm{G}}$ ratio first increased and then decreased (the highest $I_{\mathrm{D}} / I_{\mathrm{G}}$ ratio was obtained for $\mathrm{V} 2$ ).

This phenomenon may be attributed to the decreasing $\mathrm{O}_{2}$ ratio in the reduction flame. Reducing gases were increasingly generated due to the accumulation of combustion products. Thus, the GO reduction effect became stronger, and the proportion of RGO increased simultaneously. However, a reduction in the $\mathrm{O}_{2}$ ratio of the reduction flame weakens the GO reduction effect by causing a decrease in the flame temperature. Moreover, the $I_{2 \mathrm{D}}$ of GO and RGO is mostly negligible or zero. However, in this study, CBNMs should also consist of AC in terms of a clear and broad range of $I_{2 \mathrm{D}}$ observing in the CBNMs produced by some of the process parameters. Moreover, the CBNMs contained different ratios of GO, RGO, and $\mathrm{AC}$, which is inferred by simultaneously considering the Raman spectra and XRD patterns. In addition, for a specific ratio of $\mathrm{O}_{2}$ and $\mathrm{C}_{2} \mathrm{H}_{2}$, the processing time only affected the production rate of CBNMs (CBNF concentration).

Figure 7 displays the concentrations of the CBNMs in the CBNFs, as measured using the weighing method for V2-V4. Despite utilization of the vacuum concentration method, the weighing equipment in the authors' laboratory could not accurately detect the concentration of V1 CBNFs because this concentration was extremely low. Therefore, in the subsequent related experiments, the V1 CBNF samples were excluded. The V2, V3, and V4 configurations produced CBNM concentrations in the CBNFs of $0.0414,0.0553$, and $0.0239 \mathrm{wt} . \%$, respectively, at a processing time of $12 \mathrm{~min}$. The results revealed that, in addition to $\mathrm{V} 4$, the production rate (concentration in the CBNF) of CBNMs and the $\mathrm{O}_{2}$ flow rate were inversely proportional. Moreover, the production rate of all samples was directly proportional to the processing time. In the preparation procedure, the $\mathrm{V} 4$ configuration resulted in the most black smoke (V4 with the minimum addition of $\mathrm{O}_{2}$ ) and the highest CBNM production rate, despite the production rate being lower than that when V2 and V3 were used. The V4 configuration resulted in the generation of considerable smoke and the rapid formation of numerous carbon particles that aggregated on the water surface. While the liquid was being stirred with a magnetic stirrer (stage 1 ), it was challenging to dissolve these floating carbon particles on the water surface, which hindered the collection efficiency. Subsequently, the carbon particles were collected efficiently by the water vortex in stage 2 . However, in stages 2 and 3, obtaining suitable collection efficiency for the V4 configuration was challenging because the carbon particles generated could not be appropriately collected in stage 1 . The material analysis results indicated that processing time had no influence on the material obtained. In subsequent experiments, the V2-V4 samples obtained using a processing time of $12 \mathrm{~min}$ were adjusted to the same concentration (0.024 wt.\%) for testing and comparison.

Figure 8 displays a photograph of the experimental results obtained after $120 \mathrm{~h}$ of static positioning for the V2-V4 samples at various dispersant concentrations. The CBNM concentrations for $\mathrm{V} 2-\mathrm{V} 4$ were $0.024 \mathrm{wt} . \%$, and the numbers $0-5$ in each process parameter in the figure represent EP dispersant concentrations of $0,0.05,0.1,0.2,0.4$, and $0.8 \mathrm{wt} . \%$, respectively. As shown in Figure 8, V2-0 had the worst stability, followed by V3-0. For the sample V4-0, the difference between before and after the static positioning cannot be identified by visual inspection. Hence, a spectrometer was required to investigate the stability differences of all samples. Figure 9 plots the absorbance $R_{\text {Abs }}$ (at a wavelength of $600 \mathrm{~nm}$ ) of the CBNFs synthesized using the V2-V4 configurations with various concentrations of EP dispersant. The samples were statically positioned for $48 \mathrm{~h}$ to calculate their stability using (1). A high $R_{\mathrm{Abs}}$ value represents more severe sedimentation. The samples with the highest stability for the V2, V3, and V4 configurations were V2-5, V3-5, and V4-0, respectively; however, the stability enhancement had to be investigated further. Further research on the addition of different types and concentrations of dispersants should be considered. The results of XRD and Raman spectroscopy confirmed that the CBNMs prepared using V2-V4 were very similar but that EP dispersant addition had different effects on the materials' stability. This was primarily due to the particle size in the CBNMs, the $\mathrm{pH}$ of the CBNFs, and the interfacial effect between a CBNM and its base fluid. The estimation of suspended particle size distribution, zeta potential, and basic physicochemical characteristics requires a long time; thus, the poor stability of the samples that was observed during the measurements caused a large measurement deviation. Therefore, follow-up experiments were only performed on the samples with the highest stability for each of the V2-V4 configurations (V2-5, V3-5, and V4-0).

Figure 10 depicts the $d_{p}$ distribution of V2-5, V3-5, and V4-0 and reveals that their average $d_{p}$ was 771.1 (274.4 and 


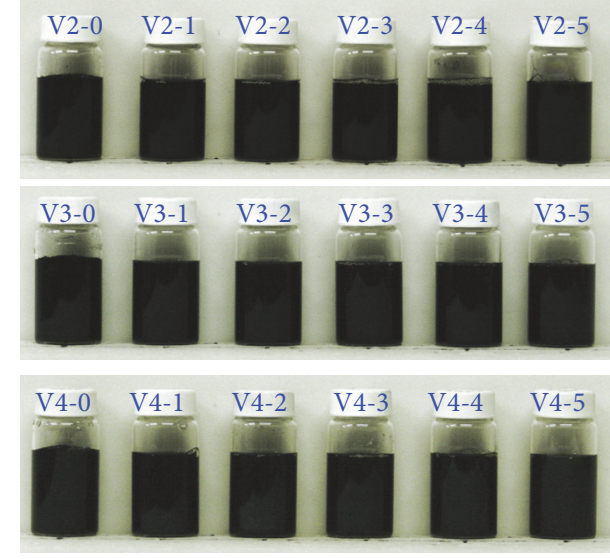

(a) Initial state

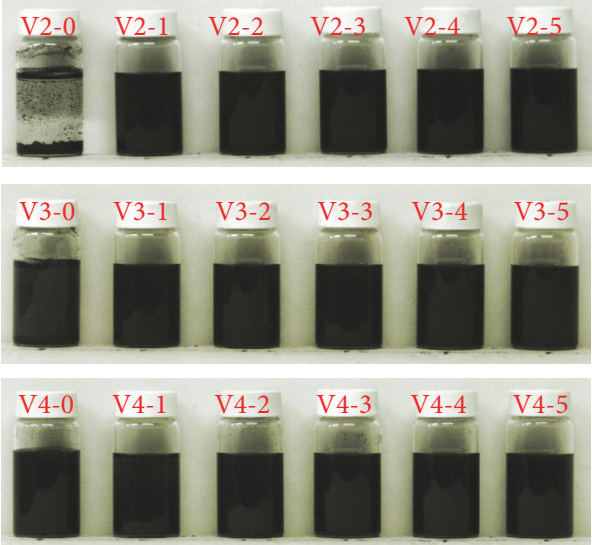

(b) After 120 hours

FIGURE 8: Photographs of the experimental results obtained using the static positioning method.

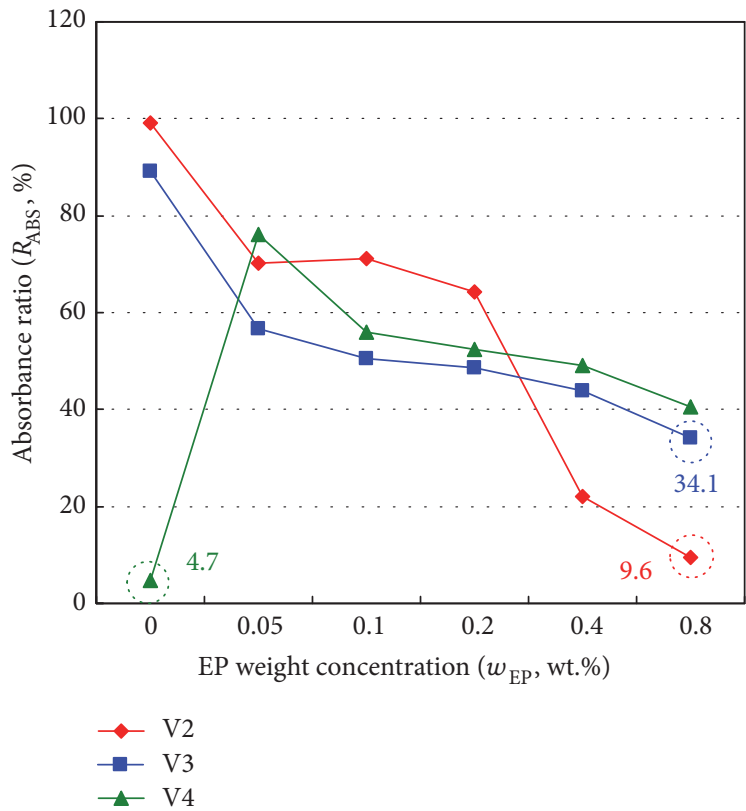

FIGURE 9: Absorbance ratios obtained using the static positioning method applied to the CBNFs obtained using various process parameter configurations.

$1278.1 \mathrm{~nm}), 680.2$, and $293.9 \mathrm{~nm}$, respectively. The results are consistent with those of the stability experiment. The minimum $d_{p}$ was obtained for a V4 sample, and this sample was highly stable even when no dispersant was added. The $d_{p}$ distribution for the V2 sample was a bimodal distribution, which is associated with the existence of a flaky material and causes a wide $d_{p}$ distribution. Figure 10 displays only one of five test results that were obtained for the $d_{p}$ distribution; the average $d_{p}$ of the five test results for each sample is listed in Table 2 .

Table 2 lists the average $d_{p}, \zeta, \rho, \mathrm{pH}, E, \mu, c_{p}$, and $k$ of the CBNFs synthesized using the various processing parameters and optimal EP dispersant concentration configurations. The values of $d_{p}$ and $\zeta$ were individually measured five times, and

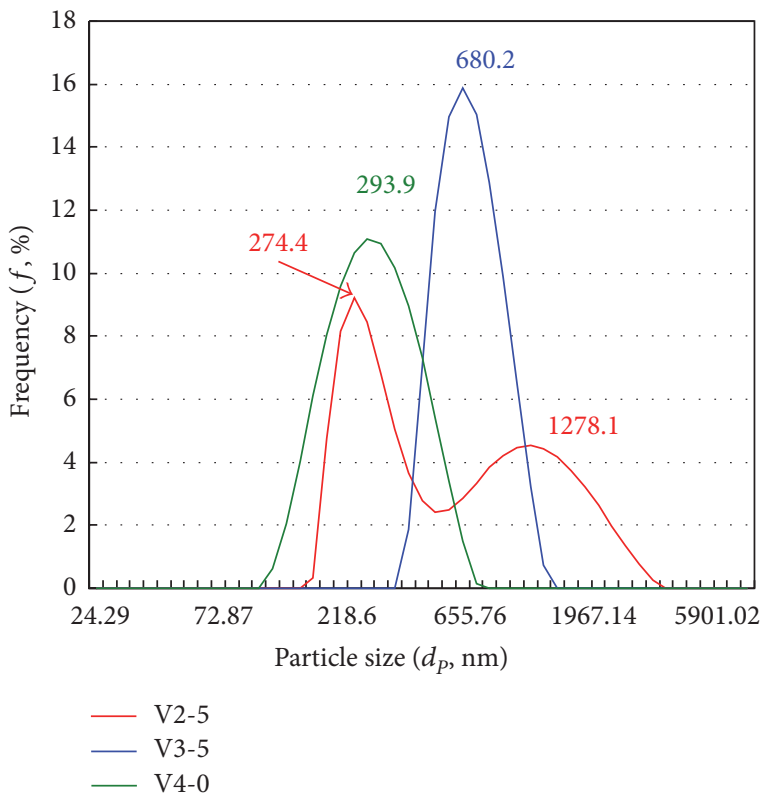

FIgure 10: Particle size distributions of the CBNFs obtained using various process parameter configurations.

then the average was calculated. The lowest $d_{p}$ was that of V40 , followed by V3-5 and V2-5. Although the differences in the samples with the same configuration parameter existed, the types of $d_{p}$ distribution were similar. The higher the absolute value of $\zeta$, the better the stability of a CBNF. The highest $\zeta$ was that for V4-0, followed by V3-5 and V2-5. In general, the $\zeta$ of an NF is within the range of \pm 10 to $\pm 30 \mathrm{mV}$, which indicates that the NF has incipient instability $[35,36]$. In this experiment, CBNFs were obtained by using various process parameters. The $\zeta$ of the CBNFs and the optimal EP dispersant concentrations of the MSVTM were within the range -12.86 to $-29.80 \mathrm{mV}$. The stability results indicated that the stability of these materials should be further improved. Further research will provide more details on what 
TABLE 2: Basic physicochemical characteristics of the CBNFs.

\begin{tabular}{|c|c|c|c|c|c|c|c|c|}
\hline \multirow{2}{*}{ Item } & \multicolumn{5}{|c|}{ Experimental data } & \multicolumn{3}{|c|}{ CR (\%) } \\
\hline & $T\left({ }^{\circ} \mathrm{C}\right)$ & Water & V2-5 & V3-5 & V4-0 & $\mathrm{V} 2-5$ & V3-5 & V4-0 \\
\hline Mean particle size $\left(d_{p}, \mathrm{~nm}\right)$ & 25 & \multirow[t]{2}{*}{ - } & 749.56 & 692.05 & 269.90 & \multirow{2}{*}{\multicolumn{2}{|c|}{ - }} & \\
\hline Zeta potential $(\zeta, \mathrm{mV})$ & 25 & & -12.86 & -13.98 & -29.80 & & & \\
\hline \multirow{3}{*}{$\begin{array}{l}\text { Density } \\
\left(\rho, \mathrm{kg} / \mathrm{m}^{3}\right)\end{array}$} & 30 & 996.27 & 996.07 & 996.43 & 996.17 & -0.02 & 0.02 & -0.01 \\
\hline & 40 & 991.87 & 992.97 & 993.00 & 992.70 & 0.11 & 0.11 & 0.08 \\
\hline & 50 & 987.33 & 987.70 & 988.70 & 987.60 & 0.04 & 0.14 & 0.03 \\
\hline \multirow{3}{*}{$\mathrm{pH}$} & 30 & 8.00 & 7.29 & 7.06 & 7.17 & -8.83 & -11.75 & -10.42 \\
\hline & 40 & 7.62 & 7.37 & 7.01 & 7.25 & -3.32 & -8.05 & -4.90 \\
\hline & 50 & 7.56 & 7.38 & 7.26 & 7.33 & -2.38 & -3.97 & -3.04 \\
\hline \multirow{3}{*}{$\begin{array}{l}\text { Electrical conductivity } \\
(E, \mu \mathrm{S} / \mathrm{cm})\end{array}$} & 30 & 110.70 & 257.00 & 280.50 & 190.50 & 132.16 & 153.39 & 72.09 \\
\hline & 40 & 113.70 & 261.67 & 285.17 & 193.32 & 130.14 & 150.81 & 70.02 \\
\hline & 50 & 120.80 & 266.50 & 286.67 & 193.92 & 120.61 & 137.31 & 60.53 \\
\hline \multirow{3}{*}{$\begin{array}{l}\text { Viscosity } \\
(\mu, \mathrm{mPa})\end{array}$} & 30 & 0.80 & 0.83 & 0.82 & 0.80 & 4.17 & 2.50 & 0.00 \\
\hline & 40 & 0.72 & 0.78 & 0.75 & 0.75 & 9.30 & 4.65 & 4.65 \\
\hline & 50 & 0.65 & 0.70 & 0.73 & 0.65 & 7.69 & 12.82 & 0.70 \\
\hline \multirow{3}{*}{$\begin{array}{l}\text { Specific heat } \\
\left(c_{p}, \mathrm{~kJ} / \mathrm{kg}^{\circ} \mathrm{C}\right)\end{array}$} & 30 & 4.183 & 4.082 & 4.165 & 4.197 & -2.40 & -0.42 & 0.34 \\
\hline & 40 & 4.182 & 4.083 & 4.172 & 4.196 & -2.36 & -0.24 & 0.33 \\
\hline & 50 & 4.182 & 4.091 & 4.175 & 4.191 & -2.17 & -0.17 & 0.22 \\
\hline \multirow{3}{*}{$\begin{array}{l}\text { Thermal conductivity } \\
(k, \mathrm{~W} / \mathrm{m} \mathrm{K})\end{array}$} & 30 & 0.618 & 0.615 & 0.623 & 0.622 & -0.44 & 0.87 & 0.73 \\
\hline & 40 & 0.629 & 0.643 & 0.633 & 0.638 & 2.21 & 0.56 & 1.29 \\
\hline & 50 & 0.644 & 0.658 & 0.654 & 0.652 & 2.26 & 1.63 & 1.29 \\
\hline
\end{tabular}

types and concentrations of dispersants can be added. Such addition can improve the stability when CBNFs are used in heat exchange systems, which require long-term stability.

The density test results for the CBNFs revealed that $\rho$ and temperature were inversely proportional. Hence, there was no significant difference between the $\rho$ of a CBNF and that of water (within the instrumental error) due to the low concentration of CBNM in a CBNF. The highest CRs of $\rho$ for V2-5, V3-5, and V4-0 were, respectively, $0.11 \%, 0.14 \%$, and $0.08 \%$ compared with water for the entire range of sample temperature.

The $\mathrm{pH}$ test results indicated that the $\mathrm{pH}$ of the CBNFs was lower than that of water because $\mathrm{CO}_{2}$ dissolved in the water to form carbonic acid during the combustion process, which slightly lowered the $\mathrm{pH}$ of the CBNFs. The highest CRs of the $\mathrm{pH}$ for $\mathrm{V} 2-5, \mathrm{~V} 3-5$, and $\mathrm{V} 4-0$ were $-8.83 \%,-11.75 \%$, and $-10.42 \%$, respectively, compared with water for the entire range of sample temperature.

Increasing the concentration of solid particles in an NF generally increases the $E$ of that NF. Moreover, the addition of ionic dispersants (e.g., SDBS or SDS) can cause $E$ to increase several times. The rapid movement of ions and suspended particles in NFs also increases the $E$ of NFs at a high temperature. In this study, the EP dispersant employed was a nonionic dispersant and thus minimally affected $E$. The EP dispersant was less effective than an ionic dispersant with regard to the effect of dispersant addition on $E$. The highest CRs of $E$ for V2-5, V3-5, and V4-0 were $132.16 \%$, $153.39 \%$, and $72.09 \%$, respectively, compared with water for the entire range of sample temperature. The experimental results revealed that the EP dispersant had a considerable effect on the $E$ of the CBNFs. However, the effect was weaker than that of an ionic dispersant.

CBNFs have a higher $\mu$ than their base fluids (singlephase fluid) because CBNFs are solid-liquid mixtures (twophase fluids). In general, the pressure drop and transport energy consumption in the pipeline increase as the $\mu$ of the working fluid is increased. However, most NFs are non-Newtonian fluids with shear thinning behavior, which causes $\mu$ to decrease at high flow rates or limits its increase. Consequently, rheological experiments were required to understand the relationships between $\mu$, pressure drop, and flow rate. The highest CRs of $\mu$ for V2-5, V3-5, and V4-0 were $9.30 \%, 12.82 \%$, and $4.65 \%$, respectively, compared with water for the entire range of sample temperature.

On the basis of the concept of a solid-liquid mixture, adding a material with a $c_{p}$ lower than that of water forms a suspension that has a $c_{p}$ lower than that of water. The experimental results revealed that the $c_{p}$ of V2-5 to V3-5 were lower than that of water; however, the $c_{p}$ of V4-0 was slightly higher than that of water. This may be attributed to the EP dispersant, the solid-liquid interface, and experimental 
deviation. The highest CRs of $c_{p}$ for V2-5, V3-5, and V40 were $-2.40 \%,-0.42 \%$, and $0.34 \%$, respectively, compared with water for the entire range of sample temperature.

Most studies indicate that the $k$ of an NF is higher than that of the NF's base fluid. The $k$ of the CBNFs in this study was slightly higher than that of water under most sample temperatures and process parameters. Nonetheless, the difference between the $k$ of the CBNFs was small. This was primarily due to the low concentration of CBNMs and the only weak effect that the CBNFs had on the enhancement of $k$ under instrumental deviation. The highest CRs of $k$ for V2-5, V3-5, and V4-0 were $2.26 \%, 1.63 \%$, and $1.29 \%$, respectively, compared with water for the entire range of the sample temperature.

\section{Conclusions}

In this study, an MSVTM was used to fabricate CBNFs by using a one-step synthesis process. The CBNFs were synthesized using $\mathrm{O}_{2}-\mathrm{C}_{2} \mathrm{H}_{2}$ combustion flames with different flow rate ratios of $\mathrm{O}_{2}-\mathrm{C}_{2} \mathrm{H}_{2}$ (V1-V4). The characteristics of the $\mathrm{CBNF}$ and suspended CBNMs were examined using suitable instruments and test methods. The findings of this study are summarized as follows:

(i) The CBNMs in the CBNFs were mainly spherical. Flaky CBNMs were also observed. The $d_{p}$ of the spherical CBNMs was approximately 20-50 nm. For V1-V4, the CBNMs consisted of GO, RGO, and AC.

(ii) The CBNM production rate was affected by the processing time. Moreover, the processing time did not influence the morphology and material of CBNM. For a processing time of $12 \mathrm{~min}$, the V2, V3, and V4 configurations resulted in CBNM concentrations of $0.0414,0.0553$, and 0.0239 wt. $\%$, respectively.

(iii) The CBNFs prepared using the V4 configuration had optimal stability without the requirement of adding an EP dispersant. The $\zeta$ of the CBNFs indicated that the materials had incipient instability $(\zeta<$ $30 \mathrm{mV}$ ) even with the addition of the EP dispersant. Hence, further research is required on the addition of different types and concentrations of dispersants to enhance the feasibility of practical application of CBNFs.

(iv) The highest enhancement ratios of $\mu$ for V2-5, V3-5, and V4-0 were $9.30 \%, 12.82 \%$, and $4.65 \%$, respectively, higher than that of water for the entire range of sample temperatures. In addition, addition of EP dispersant considerably increased the $\mu$ of the CBNFs.

(v) The highest enhancement ratios of $k$ for V2-5, V3-5, and V4-0 were $2.26 \%, 1.63 \%$, and $1.29 \%$, respectively, higher than that of water for the entire range of sample temperatures.

\section{Conflicts of Interest}

The authors declare that they have no conflicts of interest.

\section{Authors' Contributions}

Ching-Min Cheng and Shang-Pang Yu designed and planned the MSVTM. Ching-Min Cheng and Shang-Pang Yu designed the experiment and fabricated the samples. ShangPang Yu and Tun-Ping Teng carried out the measurements. Ching-Min Cheng, Shang-Pang Yu, and Tun-Ping Teng analyzed the measurements. Ching-Min Cheng, Shang-Pang $\mathrm{Yu}$, and Tun-Ping Teng wrote and revised the paper. All authors read and approved the final manuscript.

\section{Acknowledgments}

The authors would like to thank the Ministry of Science and Technology of Republic of China (Taiwan) for their financial support to this research under Contract nos. MOST 104-2221E-003-019-MY2 and MOST 106-2221-E-003-021-MY3.

\section{References}

[1] V. Fuskele and R. M. Sarviya, "Recent developments in nanoparticles synthesis, preparation and stability of nanofluids," Materials Today: Proceedings, vol. 4, no. 2, Part A, pp. 4049-4060, 2017.

[2] A. K. Sharma, A. K. Tiwari, and A. R. Dixit, "Rheological behaviour of nanofluids: A review," Renewable \& Sustainable Energy Reviews, vol. 53, pp. 779-791, 2016.

[3] S. Lee, S. U. Choi, S. Li, and J. A. Eastman, "Measuring thermal conductivity of fluids containing oxide nanoparticles," Journal of Heat Transfer, vol. 121, no. 2, pp. 280-289, 1999.

[4] Babita, S. K. Sharma, and S. M. Gupta, "Preparation and evaluation of stable nanofluids for heat transfer application: A review," Experimental Thermal and Fluid Science, vol. 79, pp. 202-212, 2016.

[5] N. A. Che Sidik, M. Mahmud Jamil, W. M. A. Aziz Japar, and I. Muhammad Adamu, "A review on preparation methods, stability and applications of hybrid nanofluids," Renewable \& Sustainable Energy Reviews, vol. 80, pp. 1112-1122, 2017.

[6] R. K. Singh, A. K. Sharma, A. R. Dixit, A. K. Tiwari, A. Pramanik, and A. Mandal, "Performance evaluation of aluminagraphene hybrid nano-cutting fluid in hard turning," Journal of Cleaner Production, vol. 162, pp. 830-845, 2017.

[7] H. Yang, H. Cui, W. Tang, Z. Li, N. Han, and F. Xing, "A critical review on research progress of graphene/cement based composites," Composites Part A: Applied Science and Manufacturing, vol. 102, pp. 273-296, 2017.

[8] M. N. A. W. M. Yazid, N. A. C. Sidik, and W. J. Yahya, "Heat and mass transfer characteristics of carbon nanotube nanofluids: A review," Renewable \& Sustainable Energy Reviews, vol. 80, pp. 914-941, 2017.

[9] N. A. C. Sidik, M. N. A. W. M. Yazid, and S. Samion, "A review on the use of carbon nanotubes nanofluid for energy harvesting system," International Journal of Heat and Mass Transfer, vol. 111, pp. 782-794, 2017.

[10] R. Geetha Bai, N. Ninan, K. Muthoosamy, and S. Manickam, "Graphene: A versatile platform for nanotheranostics and tissue engineering," Progress in Materials Science, vol. 91, pp. 24-69, 2018.

[11] K. Y. Leong, K. Z. Ku Ahmad, H. C. Ong, M. J. Ghazali, and A. Baharum, "Synthesis and thermal conductivity characteristic of hybrid nanofluids - A review," Renewable \& Sustainable Energy Reviews, vol. 75, pp. 868-878, 2017. 
[12] Y. Ishida, S. Udagawa, and T. Yonezawa, "Understanding the primary and secondary aggregation states of sputtered silver nanoparticles in thiolate matrix and their immobilization in resin," Colloids and Surfaces A: Physicochemical and Engineering Aspects, vol. 504, pp. 437-441, 2016.

[13] M. T. Nguyen, T. Yonezawa, Y. Wang, and T. Tokunaga, "Double target sputtering into liquid: A new approach for preparation of Ag-Au alloy nanoparticles," Materials Letters, vol. 171, pp. 75-78, 2016.

[14] M. T. Nguyen, H. Zhang, L. Deng, T. Tokunaga, and T. Yonezawa, "Au/Cu Bimetallic Nanoparticles via Double-Target Sputtering onto a Liquid Polymer," Langmuir, vol. 33, no. 43, pp. 12389-12397, 2017.

[15] M. Farajimotlagh, R. Poursalehi, and M. Aliofkhazraei, "Synthesis mechanisms, optical and structural properties of $\eta-\mathrm{Al}_{2} \mathrm{O}_{3}$ based nanoparticles prepared by DC arc discharge in environmentally friendly liquids," Ceramics International, vol. 43, no. 10, pp. 7717-7723, 2017.

[16] Y. Hayashi, N. Takada, Wahyudiono, H. Kanda, and M. Goto, "Synthesis of hydrophilic carbon nanoparticles from amino acids by pulsed arc discharge over aqueous solution in argon under near-critical pressure," The Journal of Supercritical Fluids, vol. 120, pp. 403-407, 2017.

[17] H. Zhang, G. Zou, L. Liu et al., "Synthesis of silver nanoparticles using large-area arc discharge and its application in electronic packaging," Journal of Materials Science, vol. 52, no. 6, pp. 33753387, 2017.

[18] D. Amans, M. Diouf, J. Lam, G. Ledoux, and C. Dujardin, "Origin of the nano-carbon allotropes in pulsed laser ablation in liquids synthesis," Journal of Colloid and Interface Science, vol. 489, pp. 114-125, 2017.

[19] G. Palazzo, G. Valenza, M. Dell’Aglio, and A. De Giacomo, “On the stability of gold nanoparticles synthesized by laser ablation in liquids," Journal of Colloid and Interface Science, vol. 489, pp. 47-56, 2017.

[20] N. Krstulović, P. Umek, K. Salamon, and I. Capan, "Synthesis of Al-doped $\mathrm{ZnO}$ nanoparticles by laser ablation of $\mathrm{ZnO}: \mathrm{Al}_{2} \mathrm{O}_{3}$ target in water," Materials Research Express, vol. 4, no. 10, 2017.

[21] A. Sathya, S. Kalyani, S. Ranoo, and J. Philip, "One-step microwave-assisted synthesis of water-dispersible $\mathrm{Fe}_{3} \mathrm{O}_{4}$ magnetic nanoclusters for hyperthermia applications," Journal of Magnetism and Magnetic Materials, vol. 439, pp. 107-113, 2017.

[22] S. Golestan, A. A. Mirzaei, and H. Atashi, "Fischer-Tropsch synthesis over an iron-cobalt-manganese (ternary) nanocatalyst prepared by hydrothermal procedure: Effects of nanocatalyst composition and operational conditions," International Journal of Hydrogen Energy, vol. 42, no. 15, pp. 9816-9830, 2017.

[23] S. Golestan, A. A. Mirzaei, and H. Atashi, "Kinetic and mechanistic studies of Fischer-Tropsch synthesis over the nano-structured iron-cobalt-manganese catalyst prepared by hydrothermal procedure," Fuel, vol. 200, pp. 407-418, 2017.

[24] T.-P. Teng, W.-P. Wang, and Y.-C. Hsu, "Fabrication and Characterization of Nanocarbon-Based Nanofluids by Using an Oxygen-Acetylene Flame Synthesis System," Nanoscale Research Letters, vol. 11, no. 1, article no. 288, 2016.

[25] T. X. Phuoc, M. Massoudi, and R. H. Chen, "Viscosity and thermal conductivity of nanofluids containing multi-walled carbon nanotubes stabilized by chitosan," International Journal of Thermal Sciences, vol. 50, no. 1, pp. 12-18, 2011.

[26] S. Harish, K. Ishikawa, E. Einarsson et al., "Enhanced thermal conductivity of ethylene glycol with single-walled carbon nanotube inclusions," International Journal of Heat and Mass Transfer, vol. 55, no. 13-14, pp. 3885-3890, 2012.

[27] F.-C. Li, J.-C. Yang, W.-W. Zhou, Y.-R. He, Y.-M. Huang, and B.-C. Jiang, "Experimental study on the characteristics of thermal conductivity and shear viscosity of viscoelastic-fluidbased nanofluids containing multiwalled carbon nanotubes," Thermochimica Acta, vol. 556, pp. 47-53, 2013.

[28] D. K. Agarwal, A. Vaidyanathan, and S. Sunil Kumar, "Experimental investigation on thermal performance of kerosenegraphene nanofluid," Experimental Thermal and Fluid Science, vol. 71, pp. 126-137, 2016.

[29] T. Maré, S. Halelfadl, O. Sow, P. Estellé, S. Duret, and F. Bazantay, "Comparison of the thermal performances of two nanofluids at low temperature in a plate heat exchanger," Experimental Thermal and Fluid Science, vol. 35, no. 8, pp. 1535-1543, 2011.

[30] T.-P. Teng and C.-C. Yu, "Heat dissipation performance of MWCNTs nano-coolant for vehicle," Experimental Thermal and Fluid Science, vol. 49, pp. 22-30, 2013.

[31] W.-W. Liu, S.-P. Chai, A. R. Mohamed, and U. Hashim, "Synthesis and characterization of graphene and carbon nanotubes: a review on the past and recent developments," Journal of Industrial and Engineering Chemistry, vol. 20, no. 4, pp. 11711185, 2014.

[32] S. M. S. Murshed and C. A. Nieto De Castro, "Superior thermal features of carbon nanotubes-based nanofluids - A review," Renewable \& Sustainable Energy Reviews, vol. 37, pp. 155-167, 2014.

[33] N. Arora and N. N. Sharma, "Arc discharge synthesis of carbon nanotubes: comprehensive review," Diamond \& Related Materials, vol. 50, pp. 135-150, 2014.

[34] M.-S. Lee, J. Kim, J. Park, and J.-U. Park, "Studies on the mechanical stretchability of transparent conductive film based on graphene-metal nanowire structures," Nanoscale Research Letters, vol. 10, no. article no. 27, 2015.

[35] R. Greenwood and K. Kendall, "Selection of suitable dispersants for aqueous suspensions of zirconia and titania powders using acoustophoresis," Journal of the European Ceramic Society, vol. 19, no. 4, pp. 479-488, 1999.

[36] D. Hanaor, M. Michelazzi, C. Leonelli, and C. C. Sorrell, "The effects of carboxylic acids on the aqueous dispersion and electrophoretic deposition of $\mathrm{ZrO}_{2}$," Journal of the European Ceramic Society, vol. 32, no. 1, pp. 235-244, 2012.

[37] ASHRAE Inc., "Chapter 30 Thermophysical properties of refrigerants," in 2009 ASHRAE Handbook-Fundamentals (SI), ASHRAE Inc, 2009.

[38] H.-J. Shin, K. K. Kim, A. Benayad et al., "Efficient reduction of graphite oxide by sodium borohydride and its effect on electrical conductance," Advanced Functional Materials, vol. 19, no. 12, pp. 1987-1992, 2009.

[39] L. Zhao, X. Guo, C. Ge et al., "Investigation of the effectiveness of PC@GO on the reinforcement for cement composites," Construction and Building Materials, vol. 113, pp. 470-478, 2016.

[40] J. Zhang, H. Yang, G. Shen, P. Cheng, J. Zhang, and S. Guo, "Reduction of graphene oxide vial-ascorbic acid," Chemical Communications, vol. 46, no. 7, pp. 1112-1114, 2010.

[41] X. Mei, X. Meng, and F. Wu, "Hydrothermal method for the production of reduced graphene oxide," Physica E: Low-dimensional Systems and Nanostructures, vol. 68, pp. 81-86, 2015.

[42] K. K. H. De Silva, H.-H. Huang, R. K. Joshi, and M. Yoshimura, "Chemical reduction of graphene oxide using green reductants," Carbon, vol. 119, pp. 190-199, 2017. 
[43] H. Wang, T. Maiyalagan, and X. Wang, "Review on recent progress in nitrogen-doped graphene: synthesis, characterization, and its potential applications," ACS Catalysis, vol. 2, no. 5, pp. 781-794, 2012.

[44] C. Castiglioni and M. Tommasini, "Raman spectroscopy of disordered and nano-structured carbon materials: The molecular approach," Óptica Pura y Aplicada, vol. 40, no. 2, pp. 169-174, 2007.

[45] F. Tuinstra and J. L. Koenig, "Raman spectrum of graphite," The Journal of Chemical Physics, vol. 53, no. 3, pp. 1126-1130, 1970.

[46] W. Chen, L. Yan, and P. R. Bangal, "Preparation of graphene by the rapid and mild thermal reduction of graphene oxide induced by microwaves," Carbon, vol. 48, no. 4, pp. 1146-1152, 2010.

[47] S. Stankovich, D. A. Dikin, R. D. Piner et al., "Synthesis of graphene-based nanosheets via chemical reduction of exfoliated graphite oxide," Carbon, vol. 45, no. 7, pp. 1558-1565, 2007.

[48] V. C. Tung, M. J. Allen, Y. Yang, and R. B. Kaner, "High-throughput solution processing of large-scale graphene," Nature Nanotechnology, vol. 4, no. 1, pp. 25-29, 2009.

[49] J. I. Paredes, S. Villar-Rodil, P. Solís-Fernández, A. MartínezAlonso, and J. M. D. Tascón, "Atomic force and scanning tunneling microscopy imaging of graphene nanosheets derived from graphite oxide," Langmuir, vol. 25, no. 10, pp. 5957-5968, 2009.

[50] S. Villar-Rodil, J. I. Paredes, A. Martínez-Alonso, and J. M. D. Tascón, "Preparation of graphene dispersions and graphenepolymer composites in organic media," Journal of Materials Chemistry, vol. 19, no. 22, pp. 3591-3593, 2009. 


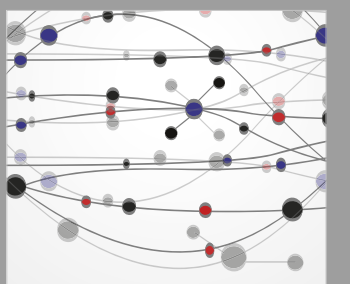

The Scientific World Journal
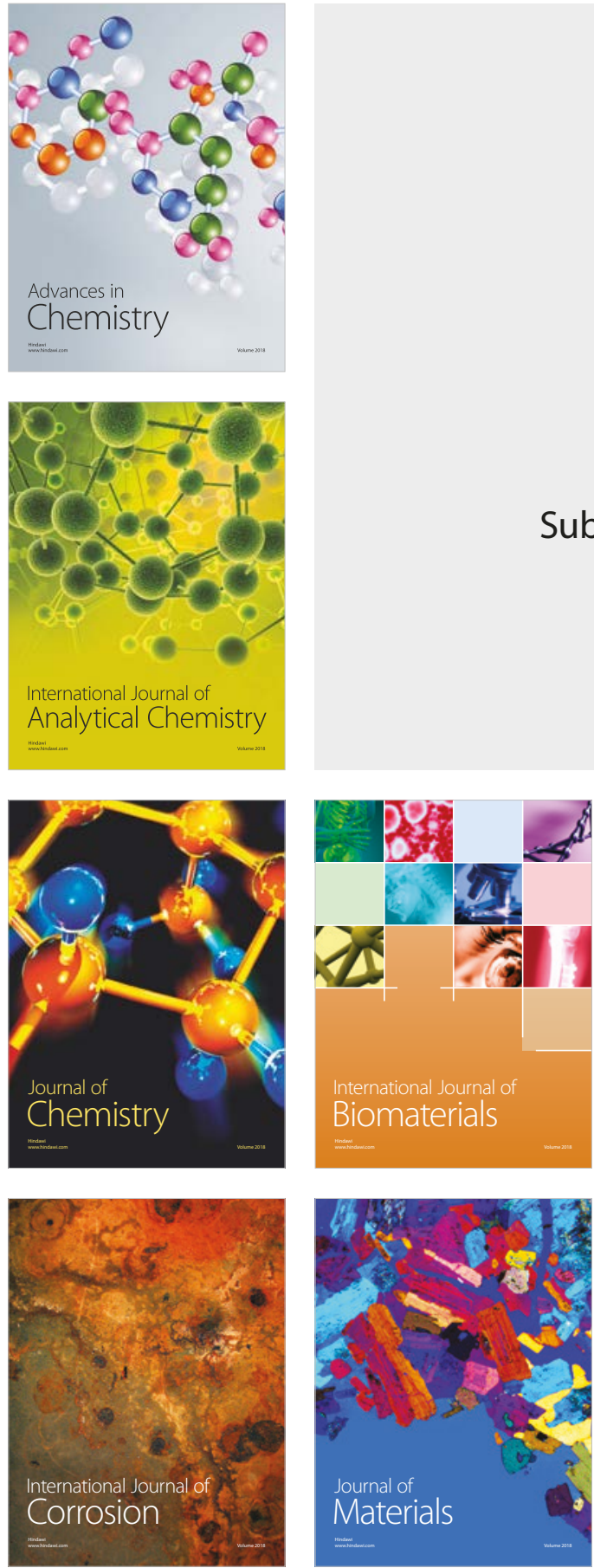

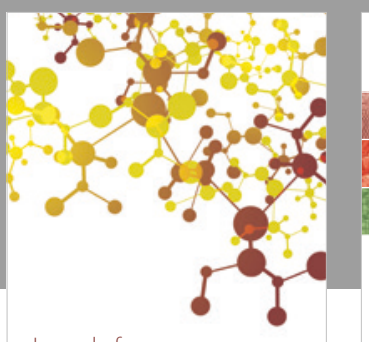

Journal of

Applied Chemistry
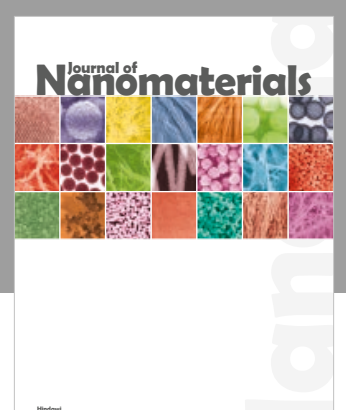

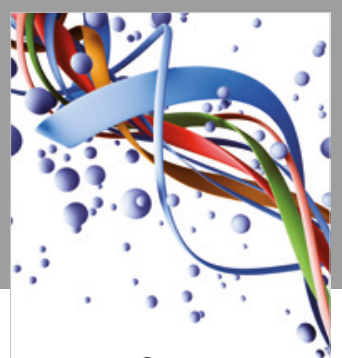

Scientifica

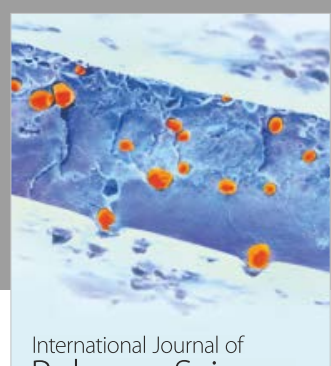

Polymer Science

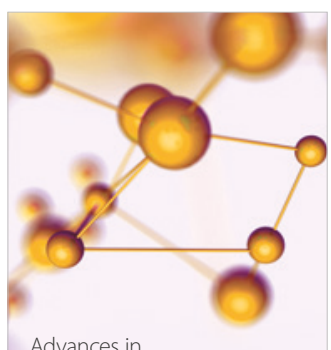

Physical Chemistry
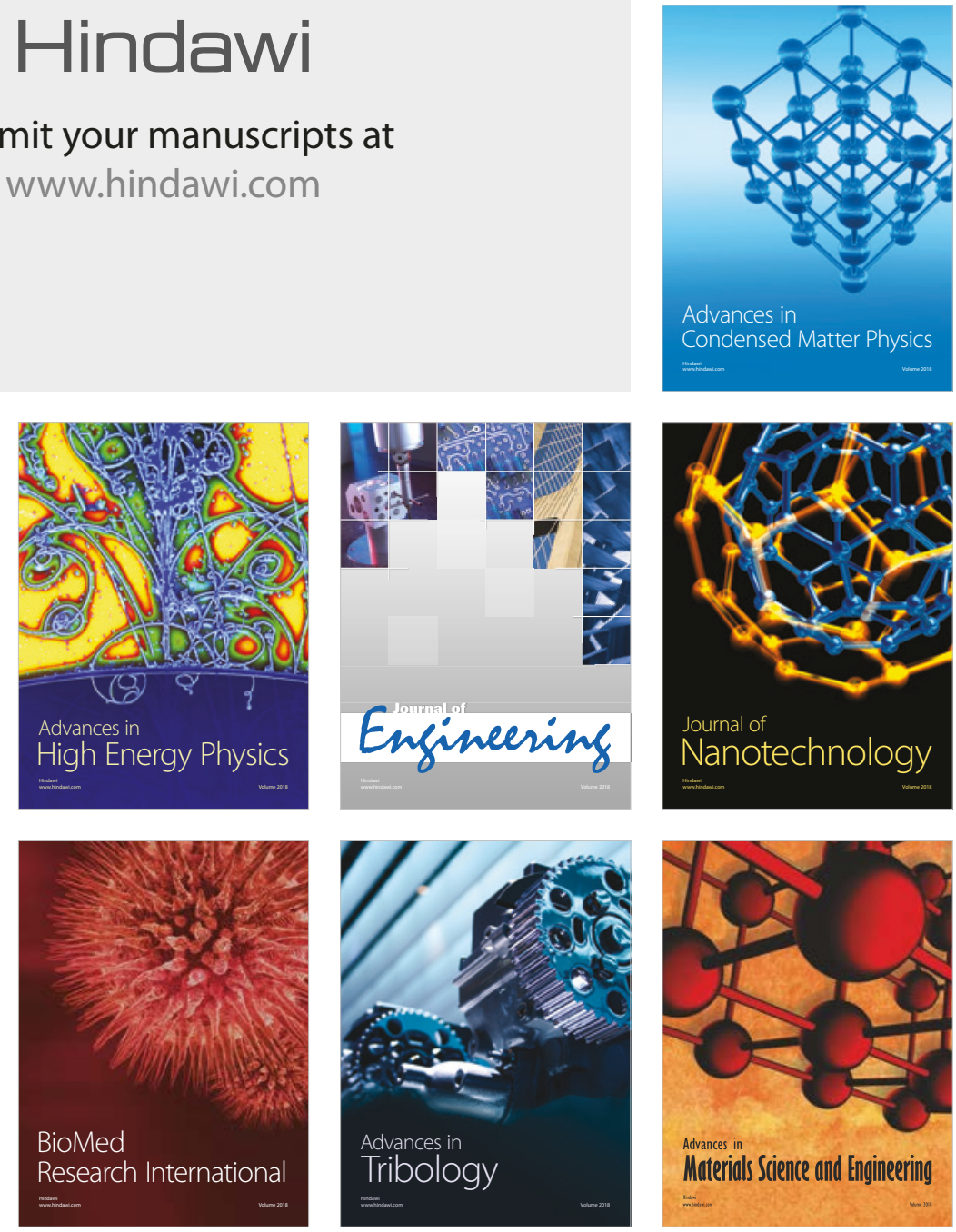